\title{
Hepatic artery reconstruction technique in liver transplantation: experience with 3,000 cases
}

\author{
Sami Akbulut^, Koray Kutluturk^, Sezai Yilmaz^ \\ Department of Surgery and Liver Transplant Institute, Inonu University Faculty of Medicine, Malatya, Turkey \\ Correspondence to: Prof. Sami Akbulut, MD, PhD, FACS. Department of Surgery and Liver Transplant Institute, Inonu University Faculty of \\ Medicine, Elazig Yolu 10. Km, Malatya 44280, Turkey. Email: akbulutsami@gmail.com. \\ Comment on: Lin TS, Vishnu Prasad NR, Chen CL, et al. What happened in 133 consecutive hepatic artery reconstruction in liver transplantation in \\ 1 year? Hepatobiliary Surg Nutr 2019;8:10-8.
}

Submitted Jan 02, 2021. Accepted for publication Feb 26, 2021.

doi: 10.21037/hbsn-21-2

View this article at: http://dx.doi.org/10.21037/hbsn-21-2

Hepatic artery reconstruction (HAR) is the most valuable step in correcting graft and recipient survival after liver transplantation (LT). Hepatic artery thrombosis (HAT) in immediate postoperative period may lead to fatal complications. Hepatic allograft is partial in a living donor liver transplantation (LDLT), and HAR is technically much more difficult than deceased donor liver transplantation (DDLT). The likelihood of HAT in LDLT is higher due to the narrower diameters of arterial vessels.

Before the microsurgical HAR period, the incidence of HAT was as high as $14-25 \%$ (1). HAR using operative microscope $(\mathrm{OM})$ was first applied by the Kyoto group, in order to reduce the HAT incidence after LDLT (2). HAT incidence after HAR with OM was reduced to $1.7 \%$ $(2,3)$. However, it is necessary to be careful when using the literature data here. Because the $25 \%$ incidence of HAT before OM belongs to the study on pediatric LDLT in 1991 of Broelsch et al. (1). In this study, hepatic artery flow was provided with aortic conduit using the interposition saphenous vein in $80 \%$ of the patients with HAT. Increased experience in LDLT and using microsurgical instruments with surgical loupes at 6 or greater magnification yielded similar or better results in adult and pediatric LDLT than those achieved with OM (4-6). Even the Kyoto group, the inventor of HAR with OM, currently performs HA anastomosis with surgical loupe (7).

Nevertheless, there is an ongoing debate that the hepatic artery anastomosis should be performed with the OM or 28 surgical loupes. As a person who is used to both techniques, 29 I would like to mention some of the disadvantages of OM: $\quad 30$

(I) Setting up OM, which has a fairly large volume, is 31 a time-consuming process and prevents the fluency 32 of the operative stages.

(II) Due to the deep working area in HAR, it is not an 34 easy task to focus the OM and use the surgeon's 35 hands effectively. $\quad 36$

(III) Diaphragmatic movements and heart pulsation 37 make the artery anastomosis difficult. These 38 difficulties are better handled with surgical loupe. $\quad 39$

(IV) There is an extremely limited field view with OM. 40 There is no chance to interfere with problems such 41 as hemorrhage outside the field of view (7). 42

(V) It is very difficult to expose the graft hepatic 43 arteries on a left lateral used for small infants 44 because of the very small abdominal cavity relative 45 to the hepatic graft. This is true for all left hepatic 46 grafts. In these cases, it is extremely difficult to 47 take proper position with operative microscope 48 and perform HAR. Therefore, we mostly perform 49 HAR before portal vein anastomosis in left grafts as 50 HAR is challenging after portal vein anastomosis. 5 Portal vein anastomosis is performed after HAR 52 and re-perfusion is provided from the portal vein 53 first, and HA is opened within a few minutes when 54

^ ORCID: Sami Akbulut, 0000-0002-6864-7711; Korak Kutluturk, 0000-0002-7030-4953; Sezai Yilmaz, 0000-0002-8044-0297. 
hemodynamics stability restored.

(VI) With OM, you have to use the "a paired Acland double microvascular clip technique". With surgical loupe and 2 separate bulldogs paired instead of Acland double microvascular clip, a clear view and safe suturing of the artery lumen will result in an easier anastomosis.

(VII) HAR with OM is mostly performed by surgeons other than transplant surgeons, like hand or plastic surgeons. This group of surgeons does not dominate the HA and its surrounding anatomy. These surgeons have not been involved in transplantation since the beginning of the operation. They are suddenly called from the social life, without responsibility and dedication to the operation and with a desire to return to their social life which is contradictory to long-term transplant surgery (8).

In our institute we used $\mathrm{OM}(\times 3-16)$ in our early experience but have modified our technique. We now use high power loupe magnification $(\times 8-8.5)$ with microvascular instruments instead of OM for HAR. Our reports demonstrate, however, that in experienced hands, results of HAR using high-power loupe optics can be equivalent or even better to OM.

When HAT develops, more than half of LT patients need re-LT. When the HAT is recognized early, revascularization procedures come into question before retransplantation. When HAT occurred, the alternatives to native HA for reanastomosis are splenic artery, interposition grafts, and LGA, according to our order of preference (9). There is no clear answer to the question of up to which day surgical revascularization can be performed in the early post-transplant period. Although surgical revascularization attempts have been performed until the second month after LT (10), the success rate of this procedure after the first 5 days is poor.

The use of LHA as a recipient artery in LDLT is controversial (11). We use LHA in HAR if the lumen is wide enough. More importantly, if you use left HA as the recipient artery in LDLT and do not dissect right HA from the biliary duct, posttransplant biliary complication rates will reduce (unpublished data).

Patients who underwent transarterial chemoembolization or transarterial radioembolization before transplantation may have a high incidence of HAT (12). Tissues must be carefully handled at the time of transplantation to prevent intimal dissection in these fragile vessels. However, this problem has been overcome as experience increased.

Although double HA rate in right lobe grafts is very low and the left lobe grafts have often multiple arteries. Unlike the right lobe grafts, both of arteries must be anastomosed, when a left lobe graft has two arterial stumps, the dominant artery is reconstructed first. After the initial HAR, another reconstruction should be performed only if no pulsating flow is observed from the remnant artery. In our cases, single HAR in left lobe LDLT with two arterial stumps did not affect patient survival or the incidence of biliary complications. The experience and lessons from 3,000 LTs were shared and important points highlighted.

\section{Acknowledgments}

Funding: None.

\section{Footnote}

Provenance and Peer Review: This article was commissioned by the editorial office of Hepatobiliary Surgery and Nutrition. The article did not undergo external peer review.

Conflicts of Interest: All authors have completed the ICMJE uniform disclosure form (available at https://hbsn. amegroups.com/article/view/10.21037/hbsn-21-2/coif). The authors have no conflicts of interest to declare.

Ethical Statement: The authors are accountable for all aspects of the work in ensuring that questions related to the accuracy or integrity of any part of the work are appropriately investigated and resolved.

Open Access Statement: This is an Open Access article distributed in accordance with the Creative Commons Attribution-NonCommercial-NoDerivs 4.0 International License (CC BY-NC-ND 4.0), which permits the noncommercial replication and distribution of the article with the strict proviso that no changes or edits are made and the original work is properly cited (including links to both the formal publication through the relevant DOI and the license). See: https://creativecommons.org/licenses/by-nc-nd/4.0/.

\section{References}

1. Broelsch CE, Whitington PF, et al. Liver transplantation in children from living related donors. Surgical techniques and results. Ann Surg 1991;214:428-37. 
2. Mori K, Nagata I, Yamagata S, et al. The introduction of microvascular surgery to HA reconstruction in livingdonor liver transplantation--its surgical advantages compared with conventional procedures. Transplantation 1992;54:263-8.

3. Inomoto $\mathrm{T}$, Nishizawa $\mathrm{F}$, Terajima $\mathrm{H}$, et al. The use of the recipient sigmoid artery for a revision of hepatic arterial reconstruction after thrombosis in living related liver transplantation. Transplantation 1995;60:881-2.

4. Guarrera JV, Sinha P, Lobritto SJ, et al. Microvascular HA anastomosis in pediatric segmental liver transplantation: microscope vs loupe. Transpl Int 2004;17:585-8.

5. Banshodani $\mathrm{M}$, Tashiro $\mathrm{H}$, Onoe $\mathrm{T}$, et al. Long-term outcome of HA reconstruction during living-donor liver transplantation. Transplant Proc 2011;43:1720-4.

6. Li PC, Thorat A, Jeng LB, et al. HA reconstruction in living donor liver transplantation using surgical loupes: Achieving low rate of hepatic arterial thrombosis in 741 consecutive recipients-tips and tricks to overcome the poor hepatic arterial flow. Liver Transpl 2017;23:887-98.

7. Yagi T, Shinoura S, Umeda $Y$, et al. Surgical rationalization of living donor liver transplantation by abolition of HA reconstruction under a fixed microscope. Clin Transplant
2012;26:877-83.

8. Yan S, Zhang QY, Yu YS, et al. Microsurgical 175 reconstruction of HA in living donor liver transplantation: 176 experiences and lessons. Hepatobiliary Pancreat Dis Int 177 2009;8:575-80.

9. Yilmaz S, Akbulut S, Kutluturk K, et al. Splenic Artery Transposition for HA Reconstruction during Liver Transplantation: Is it the Best Choice for Adequate Arterial Inflow in Extraordinary Conditions? Liver Transpl 2020. [Epub ahead of print]. doi: 10.1002/lt.25884.

10. Lin TS, Vishnu Prasad NR, Chen CL, et al. What happened in 133 consecutive hepatic artery reconstruction in liver transplantation in 1 year? Hepatobiliary Surg Nutr 2019;8:10-8.

11. Uchiyama H, Ikegami T, Soejima Y, et al. Use of recipient's left HA for artery reconstruction in right lobe living donor liver transplantation with duct-to-duct anastomosis. Transplantation 2010;89:1016-21.

12. Ince V, Ersan V, Karakas S, et al. Does Preoperative Transarterial Chemoembolization for Hepatocellular Carcinoma Increase the Incidence of HA Thrombosis After Living-Donor Liver Transplant? Exp Clin Transplant 2017;15:21-4.

Cite this article as: Akbulut S, Kutluturk K, Yilmaz S. Hepatic artery reconstruction technique in liver transplantation: experience with 3,000 cases. HepatoBiliary Surg Nutr 2021;10(2):281-283. doi: 10.21037/hbsn-21-2 